\title{
English Language Teachers' Knowledge and their Self-efficacy
}

\author{
Azadeh Zakeri \\ Azad University of Takestan, Iran \\ Email: zakeri.azadeh@gmail.com \\ Mohammad Alavi \\ University of Tehran, Iran
}

\begin{abstract}
The present research aims at exploring the relationship between novice English teachers' knowledge and their self-efficacy. A teacher knowledge test and an efficacy questionnaire were administered to 55 novice English teachers. The data were gathered from male and female novice teachers teaching at language institutes in Tehran with ages between 20 and 25. The results showed that there is a significant relationship between English Teachers Knowledge Test (TKT) and their self-efficacy. The results are discussed in the light of previous findings.
\end{abstract}

Index Terms - teacher knowledge, self-efficacy, novice teachers

\section{INTRODUCTION}

In the field of English teaching, teacher's knowledge is a neglected construct (Freeman, 2002). The study of teacher knowledge is nearly two decades old, and the nature and development of that knowledge, according to Munby et al. (2001), is only beginning to be understood by researchers in teaching and teacher education. Although teacher's knowledge has been the subject of debates since Dewey (1944), defining teacher's knowledge is still a difficult task because of the different aspects it embraces. Concerning the importance of teachers' knowledge, researchers have found that there is a high correlation between what teachers know and what they teach (Wilson et al., 1987). The contention is that the ability to teach effectively depends on the teachers' knowledge, and that teacher effectiveness is impeded if the teacher is unfamiliar with the body of knowledge taught.

The current view is that the way teachers teach is not only affected by the training they have received, it is also a result of an interaction among received, personal, experiential, and local types knowledge (Mann, 2005, p. 106). Researchers (e.g. Freeman, 2002; Mullock, 2006) have thought of teachers' actions in the classroom as grounded in some form of thinking which is shaped by teachers' knowledge, attitudes, and values. Hence, research into the nature of teachers' knowledge needs to investigate many facets of teacher thinking and beliefs.

While numerous studies have investigated the knowledge of L1 teachers (e.g., Hillocks, 1999), not much research has been conducted in the area of EFL teacher knowledge (see, however, Day, 1993; Andrews, 2003). The present study aimes at bridging a part of this gap by investigating the relationship between English teachers knowledge and teacher self-efficacy as well as the relationship between the modules of English teachers' knowledge and the components of teachers' self-efficacy.

Evidence points to powerful effects of teachers' sense of efficacy concerning their instructional activities as well as student attitudes and achievements (Atay, 2007). The construct of teacher efficacy was derived from Bandura's theory of self-efficacy (1977) and is defined as "the teacher's belief in his or her capability to organize and execute courses of action required to successfully accomplish a specific teaching task in a particular context" (Tschannen-Moran et al., 1998 , p. 22). A teacher's sense of efficacy has been found to be associated with student characteristics such as motivation, achievement, and efficacy (Tschannen-Moran et al., 1998). Many studies have demonstrated the relationship between teachers' self-efficacy and their instructional behaviors (e.g., Pajares, 1992). To the best of the researchrs' knowledge, much research has been conducted on teacher knowledge (e.g., Shulman 1987) and on selfefficacy (e.g., Ross, 1994; Tschannen-Moran et al., 1998), but little has been carried out on the relationship between these two constructs. Thus, the main purpose of this study was to investigate the relationship between teacher knowledge and teacher self-efficacy.

\section{THE CURRENT STUDY}

\section{A. Participants}

The participants of the study were 55 novice English teachers teaching at language institutes in Tehran. They were male and female with ages between 20 and 25 . The participants were guaranteed anonymity and received credit of some sort at their workplace. The criterion for selecting novice teachers was six months of teaching experience or less. 


\section{B. Instruments}

In this study, a questionnaire, i.e., the Teacher Self-Efficacy Scale (TSES) (Tschannen-Moran and Woolfolk Hoy, 2001) and a teacher knowledge test, i.e., the Teaching Knowledge Test (TKT) developed by Cambridge ESOL were used. The items in the questionnaire were answered on a 9-point Likert scale ranging from 1 (i.e., nothing) to 9 (i.e., a great deal). In the following section, these two instruments are introduced in more details.

\section{Teaching Knowledge Test (TKT)}

The Teaching Knowledge Test (TKT) is a test for teachers developed by Cambridge ESOL, a department in the University of Cambridge Local Examinations Syndicate (UCLES). The TKT consists of three modules. The first module which consists of three parts addresses language and background to learning and teaching. Part 1 of Module 1 tests respondents' knowledge of terms common in ELT. Part 2 of Module 1 tests their knowledge of factors basic to the learning of English by speakers of other languages. Part 3 of Module 1 tests respondents' knowledge of the range, function and appropriacy of the pedagogic choices available to the teacher to account for learner differences and the differences between L1 and L2 learning.

Module 2 which consists of two parts is related to planning lessons and using resources for language teaching. Although the TKT does not assume that respondents have knowledge of any particular book, it focuses on what teachers consider and do while planning their teaching of a lesson. It also assesses respondents' knowledge of how to employ resources, materials and aids in their lesson planning, how to translate teaching aims into lessons or series of lessons, how to sequence activities within lessons in a manner appropriate to particular groups of students, and how to select appropriate assessment activities.

Finally, Module 3 which consists of two parts is related to managing the teaching and learning process and focuses on what happens in the classroom in terms of the language used in it by the teacher or learners, and the teacher's ability to manage and make the most out of classroom language and interaction. This module assesses respondents' understanding of the functions of classroom language, adapting teacher language with regard to learner characteristics and learning purpose, and recognition of learner error. It also tests teachers' knowledge of the range and function of the strategies available to them for effectively managing classes. Table 1 below presents the outline of TKT.

TABLE1

DESCRIPTION AND CONTENT OF TKT

\begin{tabular}{|c|c|c|c|}
\hline Module & Desc & & T: \\
\hline \multirow[t]{4}{*}{1} & \multirow{4}{*}{$\begin{array}{l}\text { Language and background } \\
\text { to language learning and } \\
\text { teaching }\end{array}$} & Describing language and language skills & \multirow{4}{*}{80 minutes } \\
\hline & & & \\
\hline & & $\mathrm{Bac}$ & \\
\hline & & Background to language teaching & \\
\hline \multirow[t]{2}{*}{2} & \multirow{2}{*}{$\begin{array}{l}\text { Lesson planning and use of } \\
\text { resources for language } \\
\text { teaching }\end{array}$} & $\begin{array}{l}\text { Planning and preparing a lesson or } \\
\text { sequence of lessons }\end{array}$ & \multirow[t]{2}{*}{80 minutes } \\
\hline & & $\begin{array}{l}\text { Selection and use of resources and } \\
\text { materials }\end{array}$ & \\
\hline \multirow[t]{2}{*}{3} & \multirow[t]{2}{*}{$\begin{array}{l}\text { Managing the teaching and } \\
\text { learning process }\end{array}$} & $\begin{array}{l}\text { Teachers' and learners' language in the } \\
\text { classroom }\end{array}$ & \multirow[t]{2}{*}{80 minutes } \\
\hline & & Classroom management & \\
\hline
\end{tabular}

\section{Teacher Self-efficacy Scale}

The scale used in the present study is the short version of the TSES (Tschannen-Moran and Woolfolk Hoy, 2001) adapted to fit the context of ELT (English Language Teaching) by adding or substituting "English" or "learning English" for "school work" in items 1, 2, 3, 4, 6, 7, 9, 10, and 12. For example, the schoolwork in "How much can you do to motivate students who show low interest in schoolwork was replaced with learning English, and the question was posed as "How much can you do to motivate students who show low interest in learning English". The reason behind choosing the short form was because the participants had to fill out both the questionnaire and the TKT, and it was predicted that filling out the long version of the questionnaire might be tedious and boring so that the participants might reply to the items inattentively and so the outcomes of the study would be negatively affected.

The TSES consists of 12 items which were answered on a 9-point scale ranging from 1 nothing to 9 a great deal. Four items of the TSES were related to each of the three subscales: efficacy for student engagement, efficacy for classroom management, and efficacy for instructional strategies. It should be noted that the Cronbach's alpha of 0.88 assured the researchers that this questionnaire was highly reliable for assessing the participants' attitudes toward their self-efficacy.

\section{Procedure}

The TKT was administered to 55 novice English language teachers. Also, the questionnaire tapping into teacher selfefficacy was administered to these teachers. The participants were guaranteed anonymity.

\section{RESULTS}

In Table 2, descriptive statistics, including means and standard deviations for the participants' answers to the items of the TKT based on the responses of 55 English instructors are presented. As the table illustrates, the mean of the participants' answers to the items of the TKT was 142, with the standard deviation of 37.66. Also, according to the table, 
the means of the participants' answers to the items of the three modules of the TKT (i.e., language and background to language learning and teaching, lesson planning and use of resources for language teaching, and managing the teaching and learning process) are $53.25,44.31,44.58$, respectively.

As Table 2 shows, the standard deviation for language and background to language learning and teaching is 12.09, and for lesson planning and use of resources for language teaching, the figure is 16.60 . For the last subscale, namely managing the teaching and learning process, the standard deviation is 14.88 . As it can be observed, the respondents performed better on language and background to language learning and teaching, compared to the other two subscales. Moreover, they performed equally well on lesson planning and use of resources for language teaching, and managing the teaching and learning process.

TABLE 2

DESCRIPTIVE STATISTICS FOR THE PERFORMANCE ON THE TKT AND ITS MODULES

\begin{tabular}{llllll}
\hline & N & Minimum & Maximum & Mean & $\begin{array}{l}\text { Std. } \\
\text { Deviation }\end{array}$ \\
\hline TKT & 55 & 47.00 & 202.00 & 142 & 37.66 \\
Module 1 & 55 & 16 & 74 & 53.25 & 12.09 \\
Module 2 & 55 & 8 & 71 & 44.31 & 16.60 \\
Module 3 & 55 & 13 & 80 & 44.58 & 14.88 \\
& & & & & \\
\hline
\end{tabular}

The Self-efficacy questionnaire used in this study consisted of 12 questions that aimed to examine three constructs, i.e. self-efficacy for learners' engagement, self-efficacy for classroom management, and self-efficacy for instructional strategies. In Table 3, descriptive statistics, including means and standard deviations for the participants' answers to the items of the self-efficacy questionnaire based on the responses of 55 English instructors are presented. As the table shows, the mean of the participants' answers to the items of the self-efficacy questionnaire was 6.74, with the standard deviation of 1.13 .

TABLE 3

DESCRIPTIVE STATISTICS FOR THE PERFORMANCE ON THE SELF-EFFICACY QUESTIONNAIRE

\begin{tabular}{llllll}
\multicolumn{5}{c}{ DESCRIPTIVE STATISTICS FOR THE PERFORMANCE ON THE SELF-EFFICACY QUESTIONNAIRE } \\
\hline Self-efficacy & N & Minimum & Maximum & Mean & Std. Deviation \\
\hline
\end{tabular}

Also, according to Table 4, the means of the participants' answers to the items of the three subscales of the selfefficacy questionnaire (i.e., efficacy for student engagement, efficacy for class management, and efficacy for instructional strategies) are 6.62, 6.89, 6.67, respectively. As this table shows, the standard deviation for efficacy for student engagement is 1.48 , and for efficacy for class management, the figure is 1.18 . For the last subscale, namely managing the efficacy for instructional strategies, the standard deviation is 1.32 . As it can be observed, the respondents performed slightly better on efficacy for class management, followed by efficacy for instructional strategies and efficacy for student engagement.

TABLE 4

DESCRIPTIVE STATISTICS FOR THE PERFORMANCE ON THE SELF-EFFICACY QUESTIONNAIRE AND ITS COMPONENTS

\begin{tabular}{|c|c|c|c|c|c|}
\hline & $\mathrm{N}$ & Minimum & Maximum & Mean & Std. Deviation \\
\hline Efficacy for Student Engagement & 55 & 2.50 & 9.00 & 6.62 & 1.48 \\
\hline Efficacy for Class Management & 55 & 4.00 & 8.50 & 6.89 & 1.18 \\
\hline Efficacy for Instructional Strategies & 55 & 3.50 & 8.75 & 6.67 & 1.32 \\
\hline Valid N (listwise) & 55 & & & & \\
\hline
\end{tabular}

The present study aimed at determining the degree of relationship between teacher knowledge and teacher selfefficacy. Correlation analyses were conducted to determine the extent to which scores on one Teacher Knowledge Test are associated with the participants' self-efficacy. After examining the scatter plots for the variables involved in each question and assuring the linearity of the relationship, Pearson product-moment correlations were performed to explore whether a relationship exists between teachers' knowledge and their self-efficacy. The secondary purpose of the stud was to determine whether there is a relationship between the subscales of teacher self-efficacy and the three modules of TKT.

In order to test the first research question concerning the relationship between teacher knowledge and teacher selfefficacy, Pearson product-moment correlation coefficient was computed to measure the degree of relationship between English instructors' level of knowledge and their sense of self-efficacy.

As displayed in Table 5, the r-observed value is 0.33 with a significance level of 0.012 . Since this probability is smaller than the 0.05 significance level, it can be concluded that there is a significant relationship between English instructors' knowledge and their self-efficacy. 
TABLE 5

\begin{tabular}{lll} 
THE CORRELATION BETWEEN ENGLISH TEACHERS' KNOWLEDGE AND THEIR SELF-EFFICACY \\
\hline & & Self-efficacy \\
\hline \multirow{2}{*}{ TKT } & Pearson Correlation & $0.337^{*}$ \\
& Sig. (2-tailed) & 0.012 \\
& N & 55 \\
\hline
\end{tabular}

Further analysis was run to determine the relationship between English instructors' knowledge and the three subscales of self-efficacy, i.e., efficacy for classroom management, efficacy for students' engagement, and efficacy for instructional efficacy. Table 6 presents the result of Pearson product-moment correlation coefficient analysis to examine whether there is a relationship between the participants' knowledge and the subscales of self-efficacy. As displayed in this table, the r-observed value for the relationship between the participants' knowledge and their efficacy for student engagement is 0.218 with a significance level of 0.110 . Since this probability is greater than the 0.05 significance level, it can be concluded that there is not a significant relationship between English instructors' knowledge and their efficacy for student engagement.

As the table shows, the r-observed value for the relationship between the participants' knowledge and their efficacy for class management is 0.293 with a significance level of 0.030 . Since this probability is smaller than the 0.05 significance level, it means that there is a significant relationship between English instructors' knowledge and their efficacy for class management.

As for the relationship between the participants' knowledge and their efficacy for instructional strategies, as the table shows, the r-observed value is 0.377 with a significance level of 0.005 . Since this probability is smaller than the 0.05 significance level, it follows that relationship between English instructors' knowledge and their efficacy for instructional strategies is significant. Thus, the table indicates that the highest relationship is between the teachers' knowledge and their efficacy for instructional strategies followed by the relationship between the teachers' knowledge and their efficacy for class management, while there is no relationship between their knowledge and their efficacy for student engagement.

TABLE 6

THE CORRELATION BETWEEN TEACHER'S KNOWLEDGE AND THE SUBSCALES OF SELF-EFFICACY

\begin{tabular}{lllll}
\hline & & & \multicolumn{2}{c}{$\begin{array}{l}\text { Efficacy for } \\
\text { Instructional } \\
\text { Strategies }\end{array}$} \\
\hline TKT & Pearson Correlation & $\begin{array}{l}\text { Efficacy for Student } \\
\text { Engagement }\end{array}$ & $\begin{array}{l}\text { Efficacy for Class } \\
\text { Management }\end{array}$ & $0.377^{* *}$ \\
& Sig. (2-tailed) & 0.218 & $0.293^{*}$ & 0.005 \\
& $\mathrm{~N}$ & .110 & 0.030 & 55 \\
\hline
\end{tabular}

Further analysis was run to determine the relationship between English instructors' self-efficacy and the three modules of teachers' knowledge, i.e., language and background to language learning and teaching, lesson planning and use of resources for language teaching, and managing the teaching and learning process. Table 7 presents the result of Pearson product-moment correlation coefficient analysis to examine whether there is a relationship between the participants' self-efficacy and the three subscales of TKT. As displayed in this table, the r-observed value for the relationship between the participants' self-efficacy and the first module of TKT, i.e., language and background to language learning and teaching is 0.384 with a significance level of 0.004 . Since this probability is smaller than the 0.05 significance level, it can be concluded that there is a significant relationship between English instructors' self-efficacy and the first module of the TKT.

As the table shows, the r-observed value for the relationship between the participants' self-efficacy and the second module of the TKT, i.e., lesson planning and use of resources for language teaching is 0.257 with a significance level of 0.059. Since this probability is not smaller than the 0.05 significance level, it means that there is not a significant relationship between English instructors' self-efficacy and the second module of the TKT.

As for the relationship between the participants' self-efficacy and the third module of the TKT, i.e., managing the teaching and learning process, as the table shows, the r-observed value is 0.253 with a significance level of 0.062 . Since this probability is greater than the 0.05 significance level, it follows that relationship between English instructors' selfefficacy and the third module of the TKT is not significant. Thus, the table indicates that there is a relationship only between the teachers' self-efficacy and the first module of the TKT, i.e., language and background to language learning and teaching, with no relationship between the teachers' self-efficacy and the second and the third TKT subscales, i.e., lesson planning and use of resources for language teaching, and managing the teaching and learning process. 
TABLE 7

THE CORRELATION BETWEEN SELF-EFFICACY AND THE MODULES OF TKT

\begin{tabular}{|c|c|c|c|c|}
\hline & & Module 1 & Module 2 & Module 3 \\
\hline \multirow[t]{4}{*}{ Self-efficacy } & Pearson Correlation & & & \\
\hline & & $0.384^{* *}$ & 0.257 & 0.253 \\
\hline & Sig. (2-tailed) & 0.004 & 0.059 & 0.062 \\
\hline & $\mathrm{N}$ & 55 & 55 & 55 \\
\hline
\end{tabular}

The second research question raised in the present study concerned the relationship between the three modules of the TKT, i.e., language and background to language learning and teaching, lesson planning and use of resources for language teaching, and managing the teaching and learning process, and the three subscales of teachers' self-efficacy, i.e., efficacy for classroom management, efficacy for students' engagement, and efficacy for instructional efficacy.

As the results of Pearson product-moment correlation coefficient analysis, summarized in Table 8, show, the first module of the TKT, i.e., language and background to language learning and teaching, has a positive significant relationship with the efficacy for classroom management (r-observed $=0.390, p<0.01$ ) and efficacy for instructional efficacy (r-observed $=0.396, p<0.01$ ) but not with efficacy for students' engagement. The table also shows that the second module of the TKT, i.e., lesson planning and use of resources for language teaching, has a significant relationship only with the third subscale of the self-efficacy scale, i.e., efficacy for instructional efficacy (r-observed = $0.297, \mathrm{p}<0.05$ ). Finally, the third module of the TKT, i.e., managing the teaching and learning process has a positive significant relationship only with the third subscale of the self-efficacy scale, i.e., efficacy for instructional efficacy (robserved $=0.299, \mathrm{p}<0.05$ ), but not with the first two self-efficacy subscales, i.e., efficacy for classroom management and efficacy for students' engagement.

TABLE 8

THE CORRELATION BETWEEN THE SUBSCALES OF SELF-EFFICACY AND THE MODULES OF TKT

\begin{tabular}{clccc}
\multicolumn{2}{c}{ THE CORRELATION BETWEEN THE SUBSCALES OF SELF-EFFICACY AND THE MODULES OF TKT } \\
\hline
\end{tabular}

In the following section a general discussion of the findings with regard to the hypotheses tested will be put forward. Finally, the implications of the findings of the study for teacher knowledge and efficacy will be presented.

\section{DISCUSSION}

Concerning TKT, as the results showed, the respondents performed better on language and background to language learning and teaching, compared to the other two subscales. This may be justified by the fact that the novice teachers participating in the study enjoyed a good level of knowledge of the language learning process. However, they lacked the necessary skills for devising lesson plans and managing the classroom. Moreover, they performed equally well on lesson planning and use of resources for language teaching, and managing the teaching and learning process. This may imply that the participants performed equally well on the practical and demonstrative aspects of the teaching profession. As for self-efficacy, the participants performed slightly better on efficacy for class management than on efficacy for instructional strategies and efficacy for student engagement. This preliminary result shows that instructional strategies and student engagement are domains that require strengthening in teacher education. Accordingly, efforts at enhancing teacher self-efficacy of novice teachers in terms of instructional strategies and student engagement in teacher education programs may be stressed.

As the results showed, there was a significant, though low, relationship between English teachers' knowledge and their self-efficacy. This finding is in line with studies which found a positive relationship between teachers' knowledge of the language skills and their sense of efficacy (Atay, 2007; Wilson et al., 1987). It seems that English teachers' confidence about their capabilities to teach English affects their efficacy. Lack of competency in English influences teachers' self-efficacy because in analyzing the teaching tasks, teachers will make judgments based on their teaching competence to teach students speaking, listening, reading, and writing in English. Thus, lower efficacy in teaching English would lead teachers to put less effort in motivating students to learn and value English learning. Conversely, if teachers' perceived knowledge of English is high, they will be more likely to engage students in mastery experiences 
leading to the use of English as a means to communicate. The more proficient the participants judged themselves across the four skills, the higher their sense of efficacy.

The results of the study are in line with those of Chacon (2005) who found that teachers' perceived efficacy was correlated with self-reported English proficiency. However, it was observed in our study that the respondents performed slightly better on efficacy for class management, followed by efficacy for instructional strategies and efficacy for student engagement, while Chacon (2005) found that teachers' efficacy for instructional strategies was higher than efficacy for management and engagement. This calls for further research in this regard. This finding of the current study, however, is in contrast with the finding of a study by Chan (2008) who studied self-efficacy beliefs among 273 Chinese prospective and in-service teachers in Hong Kong and observed the least confidence in classroom management.

In the light of Bandura's (1977) theory, this finding is important because teachers' judgments about their teaching competence influence EFL teachers' practice in terms of efforts, goals, and challenges they set up for themselves and for their students. Evidence in this study about the relationship between teacher self-efficacy and English language proficiency highlights the importance of preparing teachers who are competent across language skills.

Also no significant relationship was found between English instructors' knowledge and their self-efficacy for student engagement. However, a significant relationship was found between English instructors' knowledge and their selfefficacy for class management and instructional strategies. Thus, the results indicate that the highest relationship is between the teachers' knowledge and their efficacy for instructional strategies followed by the relationship between the teachers' knowledge and their efficacy for class management, with no relationship between knowledge and efficacy for student engagement. This may imply that the level of novice teachers' knowledge does not, by any means, guarantee their success in engaging the learners in the process of language learning and classroom activities.

With regard to the relationship between English instructors' self-efficacy and the three modules of teachers' knowledge, the results point to a significant relationship between English instructors' self-efficacy and the first module of the TKT, i.e., language and background to language learning and teaching, with no significant relationship between English instructors' self-efficacy and the second module of the TKT, i.e., lesson planning and use of resources for language teaching. As for the relationship between the participants' self-efficacy and the third module of the TKT, i.e., managing the teaching and learning process, as the results showed, the relationship is not significant. Thus, there is a relationship only between the teachers' self-efficacy and the first module of the TKT, i.e., language and background to language learning and teaching, with no relationship between the teachers' self-efficacy and the second and the third TKT subscales, i.e., lesson planning and use of resources for language teaching, and managing the teaching and learning process. This finding can be justified on the grounds that those teachers who perceived themselves as efficacious only enjoyed a high level of knowledge in the theoretical dimensions of language learning and teaching but lacked an acceptable level of skills with respect to lesson planning and use of resources for language teaching, and managing the teaching and learning process.

The second research question raised in the present study concerned the relationship between the three modules of the TKT and the three subscales of teachers' self-efficacy. As the results showed, the first module of the TKT, i.e., language and background to language learning and teaching, had a positive and significant relationship with the efficacy for classroom management and efficacy for instructional strategies but not with efficacy for students' engagement. The results also showed that the second module of the TKT, i.e., lesson planning and use of resources for language teaching, had a significant relationship only with the third subscale of the self-efficacy scale, i.e., efficacy for instructional strategies. This is an interesting finding because those novice teachers who performed highly on lesson planning and use of resources for language teaching are expected to have a high level of skills in devising creative strategies to share their knowledge. Finally, the third module of the TKT, i.e., managing the teaching and learning process had a positive and significant relationship only with the third subscale of the self-efficacy scale, i.e., efficacy for instructional strategies, but not with the first two self-efficacy subscales, i.e., efficacy for classroom management and efficacy for students' engagement. This shows that an ability to manage the teaching and learning process can be an indication of the ability to utilize instructional strategies in the classroom.

Concerning the modules of TKT which can account for most of the variance observed in the self-efficacy questionnaire, the results indicate that only the first module of the TKT accounts for a significant proportion of the variance observed in self-efficacy scale. The results indicate that the three TKT modules can predict about 15 percent of the self-efficacy scale.

The results advocate more inquiry with regard to teacher knowledge. Delving into teacher thinking might raise several questions related to the conceptual framework and the appropriate research methodologies to address language teachers' knowledge base, although, there are still many unsolved questions about this issue (Freeman, 2002).

In essence, the results of the current study lead to the conclusion that enhancing teachers' knowledge tends to have a positive influence on their sense of efficacy. This, in turn, may lead to effective teaching and accordingly to high student achievement since a strong sense of teacher efficacy has been found to be associated with teachers' pedagogical success and student characteristics such as motivation, achievement, and efficacy (Tschannen-Moran et al., 1998). Previous studies have also pointed to the role of teacher efficacy in shaping students' attitudes toward school and subject matter, i.e., the higher the teaching efficacy of a teacher, the greater the students' interest in school and learning materials (Tschannen-Moran et al., 1998). Hence, it is expected that encouraging and assisting teachers to improve their 
knowledge may create greater student satisfaction with teachers and schools.

In the light of the results, we can justify exploiting and developing courses for EFL teachers, focusing on teachers' knowledge base. The findings of the current study, however, must be treated with caution. To the best of the researcher's knowledge, this is the first attempt to explore the relationship between EFL teachers' knowledge and their self-efficacy in an institutional context. Thus, this study should be replicated to find out whether similar results can be obtained elsewhere. In addition, since this study was conducted only in private language institutes, further research needs to be carried out at other educational settings in order to compare the results.

\section{REFERENCES}

[1] Andrews, S. J. (2003). Teacher language awareness and the professional knowledge base of the L2 teacher. Language Awareness, 12, 2, 81-95.

[2] Atay, D. (2007). Beginning teacher efficacy and the practicum in an EFL context. Teacher Development 11 (2) (2007), pp. 203219.

[3] Bandura, A. (1977). Self-efficacy: toward a unifying theory of behavioral change. Psychological Bulletin, 84, 191-215.

[4] Chacon, C. T. (2005). Teachers' perceived efficacy among English as a foreign language teachers in middle schools in Venezuela. Teaching and Teacher Education 21, 257-272.

[5] Chan, D. W. (2008). General, collective, and domain-specific teacher self-efficacy among Chinese prospective and in-service teachers in Hong Kong. Teaching and Teacher Education 24, 1057-1069

[6] Day, T. (1993). Teachers' craft knowledge: a constant in times of change? Irish Educational Studies, Volume 24, Issue 1 March 2005 , pages $21-30$

[7] Dewey, J. (1944). Democracy and education. New York: The Free Press.

[8] Freeman, D. (2002). The hidden side of the work: Teacher knowledge and learning to teach. Lang. Teach. $35: 1$-13.

[9] Shulman, L. S. (1987). Knowledge and teaching: Foundations of the new reform. Harvard Educational Review, 57, 1-22.

[10] Tschannen-Moran, M., \& Woolfolk Hoy, A. (2001). Teacher efficacy: capturing an elusive construct. Teaching and Teacher Education, 17, 783-805.

[11] Tschannen-Moran, M., Woolfolk Hoy, A. and Hoy, W.K. (1998). Teacher efficacy: its meaning and measure, Review of Educational Research 68 (2), pp. 202-248.

[12] Mullock, B. (2006). The pedagogical knowledge base of four TESOL teachers. Modern Language Journal, 90, 48-66.

[13] Munby, H., Russel, T., \& Martin, A. K. (2001). Teacher knowledge and how it develops. In V. Richardson (Ed.), Handbook of research on teaching (4th ed.). Washington, DC: American Educational Research Association.

[14] Hillocks, G. (1999). Ways of thinking, ways of teaching. New York: Teachers College Press.

[15] Mann, S. (2005). The language teacher's development. Language Teaching, 38, 103-118.

[16] Pajares, M. F. (1992). Teachers' beliefs and educational research: cleaning up a messy construct. Review of Educational Research, 62(3), 307-333.

[17] Ross, J. A. (1994). The impact of an inservice to promote cooperative learning on the stability of teacher efficacy. Teaching and Teacher Education, 10, 381-394.

[18] Wilson, S. M., Shulman, L. S., \& Richert, A. E. (1987). "150 different ways" of knowing: Representations of knowledge in teaching. In J. Calderhead (Ed.), Exploring teachers' thinking (pp. 104-124). London: Cassell.

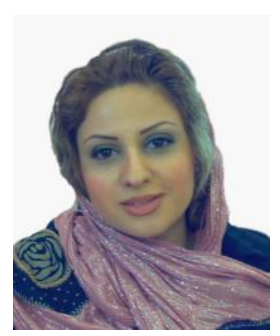

Azadeh Zakeri, born in Tehran/Iran in 1979, is an M.A. graduate in teaching English as a foreign language, from Azad University of Takestan. She completed her M.A. thesis on the relationship between teachers' knowledge, teachers' self-efficacy, and teachers' collective efficacy. She graduated from the same university in English translation.

She has been actively involved in teaching English, training English teachers, mentoring, and supervising them at different language teaching centers in Tehran. One of her publications includes: Rahmany, R. \& Zakeri, A. (2010). Rahnama M.A. Preparation Reference Book. Rahnama Publications. Tehran, Iran.

She is currently a Senior Expert of Planning with National Iranian Tanker Company (NITC).

Mohammad Alavi is an assistant professor at the University of Tehran. He did his Ph.D. in Applied Linguistics as Lancaster University, UK in 1997 and his M.A. in TEFL at 1990 from Tarbiat Modarres University, Tehran, Iran. Some of his publications include: Alavi M. (2008). Deriving unknown word meaning from context: Is it reliable? RELC Journal,Vol.39/1. Alavi M. (2005). On the adequacy of verbal protocol in examining an underlying construct of a test. Studies in Educational Evaluation. Vol 31 , Issue 1. Elsevier Science Ltd. 